Aus der I. Medizinischen Universitätsklinik in Berlin. (Direktor: Geh.-Rat His.)

\section{Zur Kenntnis der Colitis cystica.}

Von E. Keeser, Volontär an der Klinik.

Das Krankheitsbild der Colitis cystica ist zwar schon seit längercr Zeit bekannt; da es sich jedoch um eine Im ganzen seltene Darmaffektion handelt, über deren Genese, pathologische Anatomie und Therapie noch manche Frage der Beantwortung und Klärung harrt, so dürfte es von Wert sein, wenn die Aufmerksamkeit einmal wieder auf dieses Krankheitsbild gelenkt wird.

Ursprïnglich brachte man die Colitis cystica in direkte Beziehung zur Ruhr, und erst Orth ${ }^{1}$ ) hat darauf hingewiesen, da $B$ es sich bei dieser Krankheit zwar sehr häufig um die Folge einer Dysenterie handelt, daß aber die Fälle von entzündlicher Schleimzystenbildung im Dickdarm durchaus nicht alle als gleichwertig autzufassen sind und notwendig auf eine vorausgegangene dysenterische Infektion hinzuweisen brauchen. $\mathrm{Zu}$ dem gleichen Ergebnis kam auf Grund zahlreicher Beobachtungen $W \circ \circ \mathrm{d}^{2} \mathrm{add}^{2}$ ), der feststellte, $\mathrm{da} B$ die Colitis cystica in allen Lebensaltern vorkommt und die Folge beliebiger chronischer Darmkatarrhe sein kann. Nach der Lage der Zysten unterscheidet Orth eine Colitis cystica superficialis (mucosae) und eine Colitis cystica profunda (submucosae). Allerdings sind die Fälle von Colitis cystica superficialis offenbar selten, denn z. B. Löhlein's) hat nie einen reinen Fall gesehen. Auch von diesem pathologisch-anatomischen Gesichtspunkt aus bietet ein Fall von Colitis cystica Interesse, der letzthin in unserer Klinik beobachtet wurde.

Es handelt sich um die 54 Jahre alte Frau $M$. L. Seit dem 40. Lebensjahr litt Patientin an zunehmender Appetitlosigkeit mit häufigen Schmerzen in der Magengegend. Als Ursache wurde Hypazidität festgestellt. 1919 traten die Magenbeschwerden stärker auf; Patientin litt an Appetitlosigkeit und magerte stark ab. In einem Berliner Krankenhaùs fand man den Leib-eingesunken, nicht druckempfindlich. Die große Kurvatur stand 2-querfingerbreit unterhalb des Nabels. Die trüfung der Magenfunktion ergab: freie $\mathrm{HCl}-$. Ges.-Azid. 20, Blut -. In Stuhl: Blut -. Indikan -. Die Rektoskopie zeigte normale Verhältnisse.

Am 18. VI. 1919 wurde Patientin gebessert entlassen. Bald darauf stellten sich jedoch wieder Schmerzen in der Magengegend und das Gefühl der Völle und des Drucks, besonders nach dem Essen, ein ; Juli 1919 wieder Krankenhausaufnahme. Der Stuhlgang war zunächst normal, doch stellten sich bald Tenesmen ein. Anfang August wurde der Stuhl dünnbreiig mit täglich 3-4 Entleerungen, die stark gärten; ihre Untersuchung auf $\mathrm{Ty}$-, $\mathrm{Tb}$ - und Dy-Bazillen hatten ein negatives Ergebnis. Am 26. VIII. wurde $\mathrm{Pa}$ tientin auf Wunsch entlassen. 8 Tage später stellten sich plötzlich so starke Diarrhöen ein, daß Aufnahme in ein Krankenhaus erfolgen mußte. Hier hatte Patientin täglich $30-40$ dünnflüssige, unwillkürliche Entleerungen; die vorgenommene Untersuchung auf spezifisclie pathogene Bakterien hatte wieder ein negatives Resultat.

Am 20. X. 1919 Aufnahme der Patientin in unsere Klinik. Ihr Aussehen bot das Bild äußerster Entkräftung und Abmagerung. Jegliches Fett im subkutanen Gewebe war geschwunden; die Haut hatte eine papierene Beschaffenheit.

Der Leib war vollständig eingesunken. Die Leberdämpfung reichte bis zum Nabel. Keine Resistenz im Abdomen nachweisbar. Gegend des Colons descendens druckempfindlich. Die Beine waren in Flexionsstellung angezogen und in dieser Stellung durch 'Muskelkontrakturen fixiert.

Die Magenuntersuchung ergab: freie $\mathrm{HCl}$, Ges.-Azid. 6 . Die Fäzes bestanden aus normalem Detritus, keine Störung der Stärke-, Fett- und Bindegewebsverdauung; die Untersuchung der Trypsinverdauung zeigte Werte, die der Norm entsprachen. Therapeutisch erhielt Frau M. Salzsäure-Pepsin, reine Eiweißkost, Astonininjektionen. Die Nahrungsaufnahme blicb jedoch äußerst gering. Allmählich stellten sich Oedeme in den Füßen ein. Dauernd litt Patientin unter großen Schmerzen im ganzen Leib. Anfang Dezember zeigte sich zeitweise Benommenheit, Mitte Dezember nahmen die Schmerzen im Leib und der Kräfteverfall $\mathrm{zu}$; am 21. XII. eriolgte Exitus.

Die Sektion ergab eine chronische Colitis haemorrhagica, zum Teil membranacea, zum Teil cystica.

Die mikroskopische Untersuchung des Kolons zeigt zystisch erweiterte Drüsenlumina in der Mukosa, die mit Zylinderepithel ausgekleidet sind. In der Submukosa starke GefäBerweiterung und -füllung. Zellige Infiltration der Schleimhaut, besonders mit Rundzellen. Diese Zysten befinden sich in sämtlichen Schnitten rein auf die Mukosa beschränkt; nirgends ist ein Durchbruch durch die Muscularis mucosae oder gar eine unterhalb des Muscularis mucosae gelegene Zyste zu sehen.

Es ist, wie erwähnt, bekannt, daß ein durch eine beliebige Ursache entstandener chronischer Darmkatarrh eine Colitis cystica hervorrufen kann, und es erhebt sich nun die Frage, was in diesem Fall die auslösende Ursache war. Stepps) hat dạrauf hingewiesen,

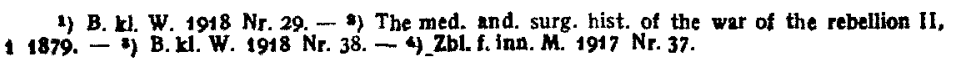

daß auf dem Boden einer chronischen gastrogenen Darmdyspepsie sich das Krankheitsbild einer mehr oder weniger tief greifenden Kolitis entwickeln kann, und zweifellos litt Frau L. seit Jahren an einer schweren Sekretionsstörung des Magens, die zu sckundären Darmschädigungen führen und eine besondere Disposition zu Darmerkrankungen schaffen mußte. Ob jedoch diese Darmdyspepsie die alleinige Ursache der Colitis cystica war oder durch die überstandene Grippe das schädigende Virus in den Darm gelangte, oder ob irgendeine andere Schälliclıkeit das beschriebene schwere Krankheitsbild auslöste, diese Frage kanı heute noch nicht mit Sicherheit beant. wortet werden. 